Type of the Paper: Article

\title{
Metabolic Syndrome in Patients of a Psychosocial Care Center in Brazil: a cross-sectional study
}

\author{
Dandara Silva ${ }^{1 *}$, Ludmila Almeida ${ }^{1}$, Livia Lugarinho ${ }^{2}$, Rodrigo Pimentel ${ }^{1}$, Antonio Marcos Gomes ${ }^{3}$, Ana Gabriela \\ Travassos ${ }^{1}$, Adriana Viana ${ }^{1}$, Monique Cerqueira ${ }^{1}$, Marcio Souza ${ }^{1}$, Anderson Sousa', Paulo Jose Barbosa ${ }^{1}$, Julita Ma- \\ ria Coelho ${ }^{1}$, Lucelia Magalhães ${ }^{4}$, Argemiro D'Oliveira ${ }^{5}$, Jorge Cavalcante ${ }^{1}$, Charles Santos ${ }^{6}$, Luiz Carlos França ${ }^{3}$, \\ Juliana Brandao ${ }^{3}$, Livia Santos' ${ }^{3}$, Helena Gomes ${ }^{3}$, Ellen Peres ${ }^{3}$, Thais Rossi ${ }^{1}$, Kairo Damasceno', Magno Mercês ${ }^{1}$.
}

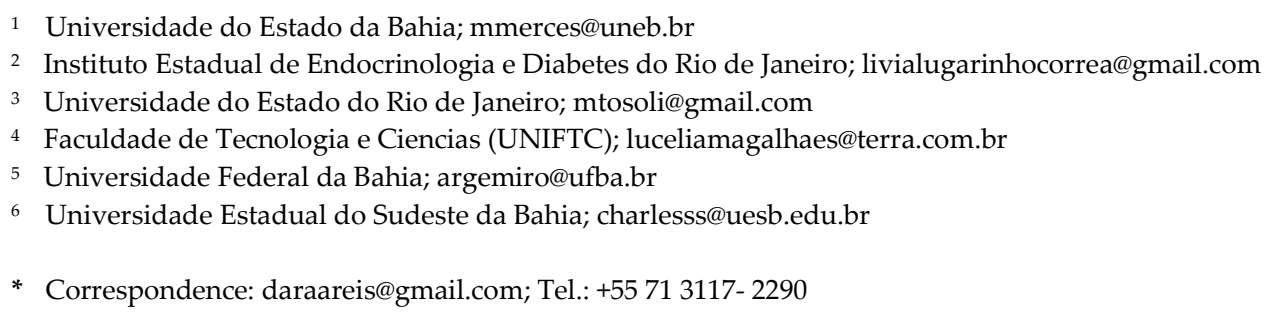

\begin{abstract}
Background: Metabolic syndrome (MS) is associated with a greater risk of morbimortality. Objective: To estimate the prevalence of Metabolic Syndrome (MS) and associated factors in patients of a Psychosocial Care Center (CAPS) in the city of Salvador, state of Bahia, Brazil. Method: Cross-sectional study set at CAPS in the city of Salvador-Bahia, between August 2019 and February 2020. MS was evaluated according to the National Cholesterol Education Program's Adult Treatment Panel III. In addition to descriptive statistics, gross and adjusted prevalence ratios were described. Results: MS was found in 100 (35.2\%) individuals, 116 (40.9\%) were obese and 165 (58.1\%) had increased waist circumference. Polypharmacy was identified in $63(22.3 \%)$ patients and 243 $(85.9 \%)$ used antipsychotics. In the gross evaluation, the female ( $P R=1.88 ; 95 \%$ CI: $1.35-2.63$ ) and the use of antidepressants ( $\mathrm{PR}=1.41 ; 95 \% \mathrm{CI}$ : 1.05-1.88) were associated with MS. After logistic regression, depression ( $\mathrm{PR}=1.86$; 95\%CI: 1.38-2.51), acanthosis ( $\mathrm{PR}=1.50$; 95\%CI: $1.18-1.90)$, use of antipsychotics ( $\mathrm{PR}=1.88$; 95\%CI: $1.13-2.75)$ and the hypertriglyceremic waist $(\mathrm{PR}=3.33$; 95\%CI: 2.48- 4.46) were associated with MS. Conclusion: The prevalence of MS alerts to multimorbidity among individuals with mental disorders and the need for clinical screening.
\end{abstract}

Keywords: Metabolic syndrome. Mental disorders. Obesity. Multimorbidity

\section{Introduction}

Metabolic Syndrome (MS) is represented by a confluence of metabolic changes related to insulin resistance, prothrombotic and inflammatory status, and it is associated with a greater chance of cardiovascular outcome, as well as an increase in overall mortality[1]. Individuals with MS are doubly able to develop diabetes mellitus [2], and 1.6 (CI: 1.28 - 2.01) more likely to die from coronary aetiology [3].

Although MS can be consisted of up to five determinants, such as elevation of triglycerides, increase of blood glucose and blood pressure, as well as the reduced HDL-cholesterol levels, the visceral adiposity increase, represented by the abdominal circumference, is the main marker of condition [4]. Following this main marker and its tendency of obesity, MS has reached larger portions of the population. According to the data from the National Health and Nutrition Examination Survey, MS affected about 16\% of non-obese Americans and 34.2\% among all 51.000 American adults analyzed in the period 2007-2012 [5]. The Brazilian data are not different and the prevalence of MS ranged from $22.7 \%[6]$ to $48.6 \%[7]$ in Brazilian groups, with lower prevalence found in 
rural populations [8].Associated with an increase in waist circumference and alteration of the metabolic pattern, MS is related to obesity and it is mainly described among women, individuals with older age and less formally educated [9]. In Brazil, regarding data from the Chronic Disease Surveillance by Telephone Survey (Vigilância de Doenças Crônicas por Inquérito Telefônico - VIGITEL), obesity had a behavior similar to MS, with higher frequency among those with less education and prevalent in the older age groups [10].

Furthermore, some groups appear to be at greater risk of MS, which is the case of people with mental disorders. In this sense, studies found a high prevalence of MS among individuals with mental illness, ranging from 29.4 to $67.9 \%$ [11,12] and a 1.58 greater risk compared to the general population[12]. More alarming data, such as the absence of dietary intervention and physical activity program, were found in the entire sample, as well as the non-treatment of glycemic alterations in $63.9 \%$ and alterations in the lipid profile in $81.7 \%$ of this same group [10], which demonstrates neglect of other patients' demands. Also, there are few data in the Brazilian care model focused on transdisciplinary monitoring and social reintegration proposed by the Psychosocial Care Centers (Centros de Atenção Psicossocial - CAPS in Portuguese).

Given this contextualization, it is still worth acknowledging the scarcity of Brazilian data and studies in the current field of mental health in Brazil. Thus, the objective of this study was to estimate the prevalence of Metabolic Syndrome (MS) and associated factors in patients of a Psychosocial Care Center in the city of Salvador, state of Bahia, Brazil.

\section{Materials and Methods}

This is a cross-sectional, descriptive and exploratory study, carried out between August 2019 and February 2020, at CAPS in the city of Salvador, Bahia, Brazil. A structured questionnaire was applied among individuals undergoing treatment for psychiatric disorders, from 18 years and older, who attended for medical care on the day of the survey. The data collection procedures were performed by two trained researchers, an endocrinologist and a medical student.

Pregnant women and patients with cirrhosis were excluded due to increase of abdominal area, as well as patients diagnosed with bulimia, anorexia, vigorexia and drug addiction once they could have laboratory alterations along with MS. It should be noted that the latter group of patients is not part of the individuals treated in the CAPS included in the study. Patients with acute psychosis were also excluded due to the difficulty to perform an analysis.

The sample was delimited based on a sample calculation for a finite population by considering the number of 1006 active individuals in the unit, average of the three months before the study, and based on the Brazilian study[12]. The study [12] found $29.4 \%$ prevalence of MS in people with mental illness during hospitalization. An absolute error of $5 \%$ and a confidence level of $95 \%$ were also considered. The value obtained through the sample calculation was $241,10 \%$ added, to suppress potential filling errors and losses, in addition to increasing the power of the study by reaching 265 individuals. The calculation was performed by using the Epi Info 7.0 software (Centers for Disease Control and Prevention, Atlanta, United States).

Sociodemographic data were obtained at the time of the interview. The psychiatric diagnosis was obtained from available medical records of the patients who agreed to participate in the research.

For the diagnosis of metabolic syndrome, proposed by the National Cholesterol Education Program's Adult Treatment Panel III report (NCEP-ATP III)[4], at least three of the following five diagnostic criteria must be detected: triglycerides $\geq 150 \mathrm{mg} / \mathrm{dl}$, blood 
glucose $\geq 110 \mathrm{mg} / \mathrm{dl}$, HDL cholesterol $<50 \mathrm{mg} / \mathrm{dl}$ for women and $<40 \mathrm{mg} / \mathrm{dl}$ for men, blood pressure $\geq 130 \times 85 \mathrm{mmHg}$ and waist circumference (WC) $\geq 88 \mathrm{~cm}$ for women and $\geq 102 \mathrm{~cm}$ for men. It is worth noting that the diagnosis of arterial hypertension and/or diabetes from medications to treat these comorbidities were also considered since they do not invalidate the MS criteria. In addition, they can be used to replace the parameters used to measure blood pressure and fasting blood glucose [4].

The hypertriglyceridemic waist phenotype is defined by the concomitant elevation of serum triglyceride and AC levels. It was first described by Lemieux in 2000 [13]. Due to the lack of consensus in the literature on waist circumference cut-off points, the values adopted in this study are recommended by the NCEP, which are defined as inadequate when WC $\geq 102 \mathrm{~cm}$ for men and $\geq 88 \mathrm{~cm}$ for women. The value $\geq 150 \mathrm{mg} / \mathrm{dl}$ was defined as abnormal for triglycerides.

Twelve hours of fasting was advised to collect laboratory tests. Enzymatic techniques were used to quantify the laboratory tests evaluated (fasting blood glucose, HDL cholesterol and triglycerides).

The clinical evaluation, as well as the application of the questionnaires, were carried out in an environment with privacy, in individual consultations performed by one of the two evaluators in the study.

The blood pressure measurement used was the average of the measurements obtained at the beginning and the end of the interview. The blood pressure was measured by a Premium ${ }^{\circledR}$ analog tensiometer with an appropriate cuff for the individual's limb, in the middle and at the end of the interview, to calculate the average of the measurements obtained. The individual should be sat with both feet on the floor for at least 5 minutes before the assessment.

The waist circumference was measured by using an ISP® inelastic tape in an imaginary line in the middle-third between the antero-superior iliac crest and the last costal arch. To calculate the body mass index (BMI), weight and height were evaluated by using a Lider ${ }^{\circledR}$ single scale, with a coupled stadiometer, model LD 1050, with $100 \mathrm{~g}$ precision, and weight variation between 2 and $300 \mathrm{~kg}$. At the time of these measurements, the patient remained without shoes and excessive clothes. Obesity was defined as BMI $\geq 30$ and overweight as BMI $\geq 25$, according to WHO criteria [14].

Prescription data were reviewed for all patients, and medical records were evaluated by the medical researcher. The drugs considered were the ones prescribed in the consultation prior to the evaluation day of the research. Polypharmacy was defined as the use of five or more psychotropic drugs [15].

MS was considered as the only outcome variable. The following variables were considered as exposure: age, sex, education, polypharmacy, class of psychotropic drugs in use, psychiatric diagnosis, presence of acanthosis nigricans, and self-reported lifestyle (physical activity, alcohol, and tobacco consumption). Age was dichotomized according to the median line (abnormality under the Shapiro-Wilk test), and eight years of education were defined as the education level cutoff point because this is the number of years for the primary school time in Brazil. The variables related to life habits were operated as follows: self-reported consumption or absence of alcohol consumption was considered for smoking and alcohol consumption, regardless the amount consumed daily, and physical activity was defined in two classes, absence/irregularity and regularly.

The Statistic Package for Social Sciences - SPSS, version 22.0, for Windows was used to statistics analysis. Descriptive statistics was used to describe the population studied as well as describing the estimate of MS prevalence. The following data were obtained: ab- 
solute and relative frequencies for categorical variables, as well as measures of central tendency and dispersion for describing the continuous variables. The description of the frequencies for psychiatric comorbidities was performed based on the distribution of each of them, between individuals with and without MS.

A bivariate analysis was then conducted to assess the gross association between independent and dependent variables (MS) by using Prevalence Ratios (PR), their respective $95 \%$ Confidence Intervals (CI), and significance level of $5 \%$ ( $p$ value $\leq 0.05$ ). The Pearson's chi-square test was used for analyzing the statistical significance of the associations found and the selection to the next step. For bivariate analyzes, continuous or polytomous independent variables were dichotomized.

For inclusion in the multivariate analysis, the Backward logistic regression model, we considered associations with a value of $\mathrm{p} \leq 0.25$ and the literature. Afterwards, it was possible to estimate the factors associated with MS by using the value of $\mathrm{p} \leq 0.05$ as the selection criterion to keep the variable in the final model. The PR and respective CI were obtained through Poisson's Robust Regression, a method also used by Coutinho, Scazufca and Menezes [16], Francisco and collaborators [17] for converting Odds Ratio (OR) (obtained in logistic regression models) into PR.

In order to analyze the adequacy of the final regression model, the following procedures and data were used: Hosmer and Lemeshow godness-of-fit, the area under the ROC curve, the VIF (Variance Inflation Factor) Statistics Test. Based on this information, possible collinearities were identified between the variables and existence of influential observation patterns.

The research protocol was approved by the Ethics Committee of the State University of Bahia, under CAAE number 13159819.6.0000.0057. All participants signed the informed consent form or the term of acceptance when applicable.

\section{Results}

Three hundred forty-four (344) patients were approached, of whom 284 agreed to participate in the research. Out of these, 284,214 had laboratory tests. The clinical and social characterization, in addition to the sample's lifestyle habits are described in table 1. There was no statistically significant difference between individuals with and without adherence to laboratory tests when evaluated: anthropometric data, blood pressure levels, and sociodemographic data. Psychiatric characteristics, such as the profile of psychiatric diagnoses and polypharmacy, also showed $p>0.05$ between the individuals that conclude and did not conclude the study.

Table 1. General description of the total users of a Psychosocial Care Center, who agreed to participate in the study, Salvador, Bahia, Brazil, 2019 ( $\mathrm{n}=284)$.

Variables

Sociodemographic

$\operatorname{Sex} \mathrm{n}(\%)(\mathrm{n}=284)$

Male

Female

Age (years) $(n=284)$
$129(45.4)$

\section{Description}

155 (54.6) 
Mean \pm SD

$44.3 \pm 11.9$

Median (IQ)

$43(36-54)$

$<43$ years old $\mathrm{n}(\%)$

$137(48.2)$

$\geq 43$ years old $n(\%)$

$147(51.8)$

Self-reported ethnicity n $(\%)(n=284)$

White

$28(8.8)$

Black

95 (33.5)

Brown

$154(54.2)$

Others

$10(3.5)$

Education $n(\%)(n=282)^{a}$

No schooling

$25(8.9)$

1-7 years

$106(37.6)$

8-12 years

$131(46.5)$

$\geq 12$ years

$20(7.1)$

Marital status n (\%) (n= 284)

Married/common-law marriage

Single

$185(65.1)$

Widowed/divorced

\section{Life Habits}

Smoking n $(\%)(n=284)$

No

$232(81.7)$

Yes

$52(18.3)$

Alcohol consumption $n(\%)(n=284)$

No

$161(91.9)$

Yes

$23(8.1)$

Regular practice of physical activity n $(\%)(\mathrm{n}=284)$

Regularly

89 (31.3)

Sedentary

$195(68.7)$

\section{Clinical}




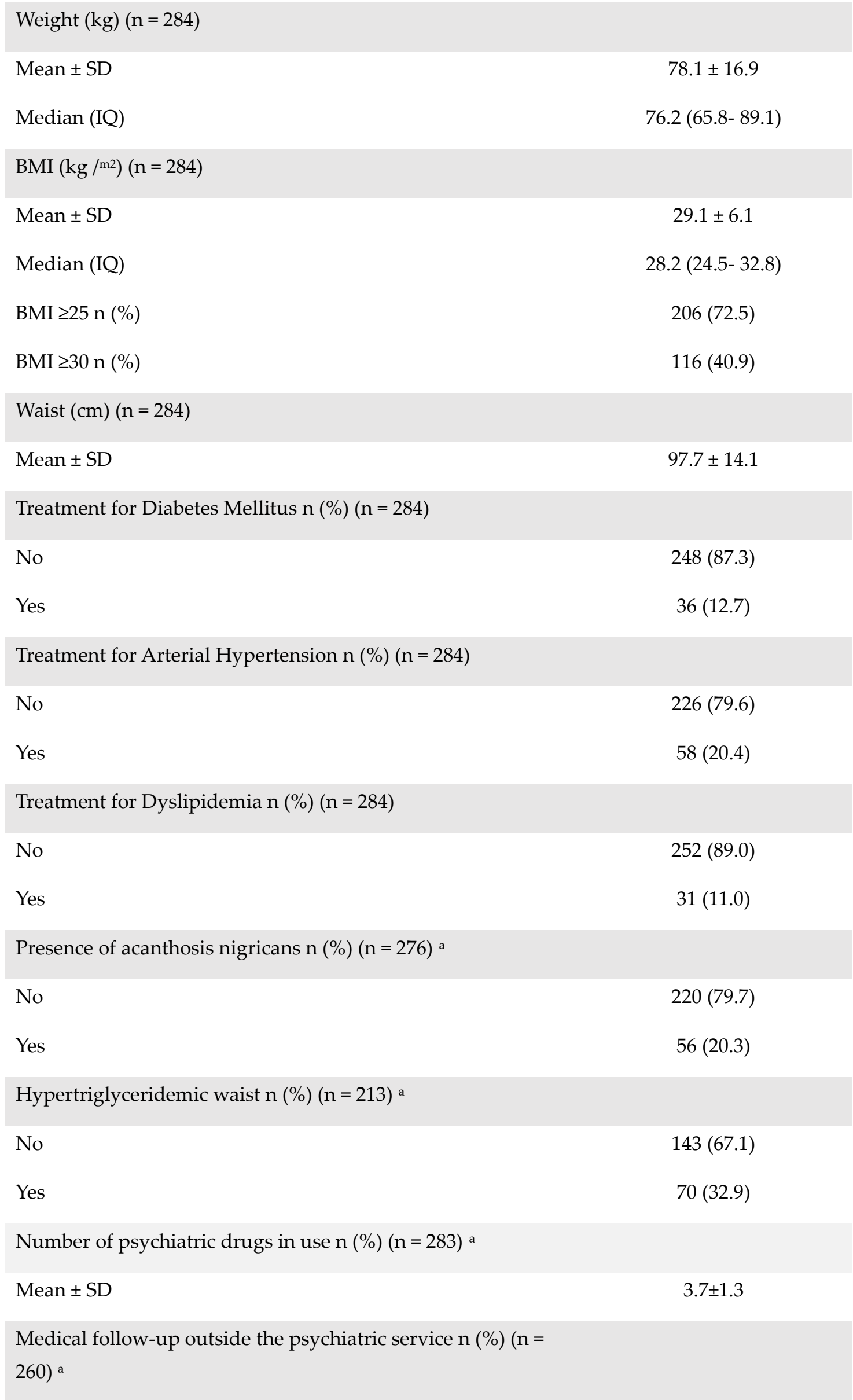


No

$146(56.2)$

Yes

$114(43.8)$

Variable with missing data; SD: standard deviation; IQ: interquartile range; BMI: body mass index

There was one death during the study period secondary to hypertriglyceridemia pancreatitis. There was no psychiatric diagnosis in the medical records for 15 (5.3\%) patients, and it was not possible to recover this data from $2(0.7 \%)$ individuals. The most prevalent psychiatric comorbidity was schizophrenia, which affected 163 (50.7\%) individuals followed by depressive disorders 57 (20.2\%). Among the other disorders not described in table 2, there were some with frequency less than $5 \%$ of the sample, such as unspecified mood disorder, personality disorder, attention deficit hyperactivity disorder, dissociative disorder, and simulation. Another group not mentioned had the so-called organic disorders as they correspond to a wide range of pathologies and were diagnosed in $29(10.3 \%)$ individuals.

Table 2. Gross prevalence ratio of metabolic syndrome and its 95\% confidence intervals according to psychiatric diagnosis and use of psychiatric drugs in the users of a Psychosocial Care Center, Bahia, Brazil, $2019(n=215)$.

\begin{tabular}{|c|c|c|c|}
\hline \multirow[b]{2}{*}{ Variables } & \multicolumn{3}{|c|}{ Metabolic Syndrome } \\
\hline & $\mathbf{P}(\%)^{b}$ & $\operatorname{PR}^{\mathrm{c}}(\mathrm{CI} 95 \%)^{\mathrm{d}}$ & p-value \\
\hline \multicolumn{4}{|c|}{ Use of psychotropic drugs } \\
\hline \multicolumn{4}{|c|}{ by class $(n=283)^{a}$} \\
\hline \multicolumn{4}{|c|}{ Antipsychotics } \\
\hline No & $9(33.3)$ & 1.00 & \\
\hline Yes & $91(48.4)$ & $1.45(0.83-2.52)$ & 0.14 \\
\hline \multicolumn{4}{|c|}{ Antidepressants } \\
\hline No & $45(39.1)$ & 1.00 & \\
\hline Yes & $55(55.0)$ & $1.41(1.05-1.88)$ & $0.02^{*}$ \\
\hline \multicolumn{4}{|c|}{ Mood stabilizers } \\
\hline No & $55(43.3)$ & 1.00 & \\
\hline Yes & $45(51.1)$ & $1.18(0.88-1.57)$ & 0.26 \\
\hline \multicolumn{4}{|c|}{ Benzodiazepines } \\
\hline No & $55(43.3)$ & 1.00 & \\
\hline Yes & $45(51.1)$ & $1.06(0.79-1.41)$ & 0.69 \\
\hline
\end{tabular}

Psychiatric diagnoses $(\mathrm{n}=$ 282) a

Schizophrenia 


\begin{tabular}{|c|c|c|c|}
\hline No & $66(50.4)$ & 1.00 & \\
\hline Yes & $34(40.5)$ & $0.80(0.59-1.09)$ & 0.16 \\
\hline
\end{tabular}

\begin{tabular}{|c|c|c|c|}
\hline \multicolumn{4}{|c|}{ Depression } \\
\hline No & $74(42.8)$ & 1.00 & \\
\hline Yes & $26(61.9)$ & $1.45(1.07-1.94)$ & $0.03^{*}$ \\
\hline
\end{tabular}

$\begin{array}{lcc}\text { Anxiety disorders } & \\ \text { No } & 94(46.5) & 1.00 \\ \text { Yes } & 6(46.2) & 0.99(0.54-1.82)\end{array}$

\section{Bipolar disorder}

$\begin{array}{lccc}\text { No } & 82(45.6) & 1.00 \\ \text { Yes } & 18(51.4) & 1.12(0.79-1.62) & 0.52\end{array}$

\section{Intellectual Disability}

No

Yes
$84(46.4)$

$16(47.1)$
1.00

$1.01(0.69-1.49)$
0.94

a variable with missing data; ${ }^{\text {bP: }}$ prevalence of the outcome between exposed and unexposed; PRc: gross prevalence ratio; 95\% dCI: 95\% confidence intervals; Pearson's chi-square test; ${ }^{*}$ statistical significance.

Antipiscotics and benzodiazepines were the most used psychotropic drugs in 243 $(85.9 \%)$ and 157 (55.5\%) of the prescriptions, respectively. Polypharmacy was identified in $63(22.3 \%)$ patients.

MS was identified in 100 individuals with a prevalence of $35.2 \%$ in the general sample and $46.5 \%$ among those with laboratory tests available. The most common alteration was the abdominal adiposity increase. One hundred sixty-five (58.1\%) individuals had an increased waist circumference, which follows the trend of obesity in the studied group as expressed in Table 1. Thus, we identified that more than half of studied population is overweight. Among individuals with obesity, $15(12.9 \%)$ had a BMI $\geq 40 \mathrm{~kg} / \mathrm{m} 2$.

The bivariate analysis between sociodemographic, clinical and psychiatric data and MS are shown in tables 2 and 3. 
Table 3. Gross prevalence ratio of metabolic syndrome and its 95\% confidence intervals according to sociodemographic and clinical variables in the users of a Psychosocial Care Center, Bahia, Brazil, 2019 (n = 215).

\section{Metabolic Syndrome}

\begin{tabular}{|c|c|c|c|}
\hline Variables & $\mathbf{P}(\%)^{b}$ & $\operatorname{PR}^{\mathrm{c}}(\mathrm{CI}$ 95\%)d & p-value \\
\hline \multicolumn{4}{|l|}{ Sociodemographic } \\
\hline \multicolumn{4}{|l|}{$\operatorname{Sex}(n=284)$} \\
\hline Male & $30(31.3)$ & 1.00 & \\
\hline Female & $70(58.8)$ & $1.88(1.35-2.63)$ & $<0.01^{*}$ \\
\hline \multicolumn{4}{|l|}{ Age (years) $(n=284)$} \\
\hline$<43$ years & $42(48.0)$ & 1.00 & \\
\hline$\geq 43$ years & $55(58.0)$ & $1.24(0.93-1.67)$ & 0.14 \\
\hline \multicolumn{4}{|l|}{$\begin{array}{l}\text { Self-referred ethnicity }(n= \\
284)\end{array}$} \\
\hline White & $10(55.6)$ & 1.00 & \\
\hline Non-white & $90(45.7)$ & $0.82(0.53-1.27)$ & 0.42 \\
\hline \multicolumn{4}{|l|}{ Education $(\mathrm{n}=282)$} \\
\hline$\geq 8$ years & $55(47.8)$ & 1.00 & \\
\hline$<8$ years & $45(45.0)$ & $0.94(0.70-1.26)$ & 0.68 \\
\hline \multicolumn{4}{|l|}{ Marital status $n(\%)(n=$} \\
\hline \multicolumn{4}{|l|}{ 284) } \\
\hline \multirow{2}{*}{$\begin{array}{l}\text { Married/common-law mar- } \\
\text { riage }\end{array}$} & $72(44.2)$ & 1.00 & \\
\hline & $28(53.8)$ & $0.82(0.60-1.11)$ & 0.22 \\
\hline
\end{tabular}

Without partner

\section{Life Habits}

Smoking $n(\%)(n=284)$

\begin{tabular}{|c|c|c|c|}
\hline No & $78(44.6)$ & 1.00 & \\
\hline Yes & $22(55.0)$ & $1.23(0.89-1.71)$ & 0.23 \\
\hline \multicolumn{4}{|c|}{$\begin{array}{l}\text { Alcohol consumption } n(\%) \\
(\mathrm{n}=284)\end{array}$} \\
\hline No & $94(47.7)$ & 1.00 & \\
\hline Yes & $6(33.3)$ & $0.69(0.35-1.36)$ & 0.24 \\
\hline
\end{tabular}




$\begin{aligned} & \text { Regular practice of physical } \\ & \text { activity } \mathrm{n}(\%)(\mathrm{n}=284)\end{aligned}$
$\begin{aligned} & \\ & \text { Regularly }\end{aligned}$
$\begin{array}{llc}\text { Sedentary } & 75(39.7) & 1.00 \\ \end{array}$

\section{Clinical}

Presence of acanthosis nigricans $n(\%)(n=276)^{a}$

No

$64(38.8)$

1.00

Yes

$34(73.9)$

$1.90(1.47-2.46)$

$<0.01^{*}$

Medical follow-up outside the psychiatric service $n$

$(\%)(\mathrm{n}=260)^{\mathrm{a}}$

Yes

45 (46.7)

1.0

No

48 (45.7)

$1.06(0.79-1.44)$

0.65

Hypertriglyceridemic waist

$n(\%)(n=213)^{a}$

No

$36(25.2)$

1.00

Yes

$62(88.6)$

$3.52(2.62-4.72)$

$<0.01^{*}$

Polypharmacy $(\mathrm{n}=283)^{\text {a }}$

$\begin{array}{ccc}\text { No } & 74(44.3) & 1.00 \\ \text { Yes } & 26(54.2) & 1.22(0.89-1.66)\end{array}$

0.23

a Variable with missing data; ${ }^{\mathrm{bP}}$ prevalence of the outcome between exposed and unexposed; PRc: gross prevalence ratio; 95\% dCI: 95\% confidence intervals; Pearson's chi-square test; ${ }^{*}$ statistical significance.

In the evaluation of the mean blood pressure, 88 (31\%) individuals had an increase in pressure compatible with the values defined as elevated by the NCEP criteria, however, only 58 (20.4\%) individuals took any blood pressure control medicine. The same was noted for glycemic control, in which blood glucose levels equal to or greater than $100 \mathrm{mg} / \mathrm{dl}$ were found in 48 people. Twenty-seven (27) of them (56.3\%) did not receive treatment for hyperglycemia. The mean value of glycemia was $104.4 \pm 38.8 \mathrm{mg} / \mathrm{dl}$ and the glycemia had values greater than or equal to $126 \mathrm{mg} / \mathrm{dl}$ for in twenty-nine individuals.

The gross prevalence ratio found an association between the variable female, the presence of acanthosis nigricans, changes in the hypertriglyceridemic waist, diagnosis of 
depression, and consumption of antidepressants as factors associated with the diagnosis of MS.

In the logistic regression, the variables: acanthosis (adjusted PR: 1.50), antipsychotic (adjusted PR: 1.76), depression (adjusted PR: 1.86) and hypertriglycididemic waist (adjusted PR: 3.33) were statistically associated to MS. It is noteworthy that the final model exhibited the ROC Curve $=0.87$ and Hosmer's test/Lemeshow's goodness of fit $=0.41$, indicating adequate discrimination power and well adjustment to the data. No collinearity was found between the variables $(\mathrm{VIF}<5)$ and patterns of influential observations were not identified (Table 4).

Table 4. Factors associated with metabolic syndrome in the users of a Psychosocial Care Center obtained through multivariate analysis.

\begin{tabular}{lll}
\hline \hline $\begin{array}{l}\text { Factors associated with Metabolic Syn- } \\
\text { drome }\end{array}$ & PRadjusted & CI (95\%) \\
\hline Acanthosis Nigricans & 1.50 & $1.18-1.90$ \\
Antipsychotics & 1.76 & $1.13-2.75$ \\
Depression & 1.86 & $1.38-2.51$ \\
Hypertriglyceridemic waist & 3.33 & $2.48-4.46$ \\
\hline Area under the ROC curve & 0.87 & \\
${ }^{¥}$ Goodness-of-fit Test & 0.41 & \\
\hline \hline
\end{tabular}

${ }^{\sharp}$ Hosmer-Lemershow

\section{Discussion}

According to the national and international literature investigated to date, this is the first study to assess the prevalence and factors associated with MS among individuals monitored by this Psychosocial Care Center.

In this study, the high prevalence of MS and overweight/obesity were generally found among individuals with mental illness, and those with depression were the most affected with a prevalence ratio of 1.86 (95\% CI 1.38-2.51). In addition to representing the most prescribed class of psychotropic drugs, antipsychotics were the only ones listed in the final model associated with MS (PR: 1.76; 95\% CI: 1.13-2.75), respectively. Despite not being kept in the multivariate analysis, females demonstrated an association with the diagnosis of MS in the bivariate analysis (PR: 1.88; 95\% CI: 1.35-2.63). No association was found between MS and the age of the individuals studied in the assessment of gross and adjusted PR.

Despite the prevalence of MS found to be higher than that described in the baseline study by Rocha et al. (29.4\%) [12], other groups had similar and even higher prevalence of MS among individuals with mental illness [18]. In a systematic review of general population studies in Brazil published in 2013, an average prevalence of $29.6 \%$ was found [8]. However, similarly to the whole world, we noticed an increase in the obesity frequency in the Brazilian population, reaching $19.8 \%$ of adults in the last survey published in 2019 [10], and which should probably contribute to the increase in morbidity caused by MS. Such analysis reinforce the findings in this study, where there is an increase of the MS frequency when compared to the study of Rocha et al [12]. 
Also, the described high prevalence of MS, the prevalence of obesity $(40.9 \%)$, and the abdominal adiposity deposition $(58.1 \%)$ found are relevant to call our attention to the possibility of a greater metabolic illness in these individuals. Such a condition may contribute to premature mortality in this group, which is already described as a reduced life-expectancy population and who reaches up to twelve years old when they have schizophrenia [19].

Similarly to the present study, other studies have also not identified an association between MS and schizophrenia [18]. However, the association between MS and depression is dangerous and should serve as a warning because it can generate a combination of risk factors for mobility impairment. Depression has been described as a cardiovascular risk factor, loss of active years, as well $[20,21]$ as associated to MS.

The use of antipsychotics, as well as the findings of previous study, were related to a higher prevalence of MS, alerting to the greater attention that should be paid to individuals who use this class of drugs [18]. Given this scenario of such a prescribed class, this study brings the need for reflection on the necessity to minimize these metabolic changes and, consequently, the cardiovascular ones.

Certain incentives are important, such as encouraging non-pharmacological measures for metabolic control and prevention, as well as promoting healthy eating and practicing physical activity often. Non-pharmacological intervention studies focused on improving metabolic and reducing obesity have been developed [22], including strategies to use remote technology [23], but the existing data are conflicting [24,25], and there are reduced cost-effectiveness descriptions of interventions promoted by a life-style program within a mentally-ill population in Canada [26].

Screening measures are easy to be applied by health service professionals and they are necessary to optimize the flow of referrals for metabolic assessment of individuals at metabolic risk. The rate of $56.2 \%$ of medical service patients do not undergo medical monitoring, nor are evaluated by a psychiatrist at the service. This therapeutic inertia has already been described by other groups [11,27].

The association between MS and acanthosis has also been described by Mercês et al.[28] in a population in northeastern Brazil. Although still controversial in the literature, the hypertriglyceridemic waist phenotype has been studied as a possible simplified marker of cardiovascular risk [29]. Based on the Kappa index, the hypertriglyceridemic waist correlated to cardiovascular risk to diagnose MS ranged from 0.42 to 0.58 [30].

An unexpected finding in this study was the non-association of MS in the final model related to the variable 'age'. The literature already found this non-association, regardless the presence of a mental disorder [28,31]. This study could justify this point based on the young age of the studied group.

The high prevalence of MS and obesity, as previously described, should serve as an alert for better clinical monitoring of individuals with mental illness, so this study demonstrates its relevance to promote a local diagnosis of these individuals' metabolic illness, which is reinforced by the literature [18]. Thus, the occurrence of MS is a marker of multimorbidity, which despite being a recent concept, has been described as more prevalent among individuals with mental illness when compared to the general population [32] and is associated with polypharmacy and worse outcomes in the population with mental illness [33].

However, we need to reflect on the limitations of this study: (I) impossibility of defining causality because only association analyzes can be established; (II) high frequency of non-adherence to laboratory tests can have an impact on the evaluation of the data 
presented, (III) obtaining information on self-reported lifestyle habits also has limitations, which need to be assessed considering the peculiarities of the participants in the study. In view of the limitations mentioned, the methodological robustness used in the present study stands out.

\title{
5. Conclusions
}

The high frequency of obesity and metabolic syndrome alert for multimorbidity in this group and brings reflections on the importance of basic assessment for metabolic changes among individuals with mental illness to provide an integrated care and to optimize their quality of life and lifespan. Depression, the use of antipsychotics, as well as the acanthosis nigricans, which are clinical and easily-obtained data, are proven to be risk factors for MS.

The data warns of the need to update the team to detect individuals at higher risk for metabolic diseases, as well as the need for an expanded medical evaluation, with the participation of the clinical physician in caring for the individual with mental illness. In this scenario, anthropometric assessment and training to recognize acanthosis nigricans can be combined to screen individuals with higher metabolic risk, fewer complex features and low cost.

\begin{abstract}
Author Contributions: Conceptualization, Dandara Almeida Reis da Silva, Lucelia Batista Neves Cunha Magalhães and Paulo Jose Bastos Barbosa; Data curation, Magno Conceição das Merces; Formal analysis, Marcio Costa de Souza, Livia Lugarinho, Thais Regis Aranha Rossi and Ana Gabriela Travassos; Investigation, Dandara Almeida Reis da Silva and Ludimila Santana de Almeida; Methodology, Monique Cerqueira, Adriana Mattos Viana and Julita Maria Freitas Coelho; Project administration, Magno Conceição das Merces; Supervision, Argemiro D’Oliveira Júnior; Validation, Helena Gomes; Visualization, Juliana de Lima Brandao, Luiz Carlos Moraes França, Livia Fajin de Mello dos Santos, Ellen Marcia Peres, Anderson de Sousa, Kairo Silvestre Meneses Damasceno and Charles Souza Santos; Writing - original draft, Dandara Almeida Reis da Silva; Writing review \& editing, Jorge Cavalcante, Rodrigo Fernandes Weyll Pimentel and Antonio Marcos Tosoli Gomes.
\end{abstract}

Funding: This research received no external funding.

Institutional Review Board Statement: The research protocol was approved by the Ethics Committee of the State University of Bahia, under CAAE number 13159819.6.0000.0057.

Informed Consent Statement: All participants signed the informed consent form or the term of acceptance when applicable.

Data Availability Statement: Data will be available on request.

Acknowledgments: Patients and the CAPS Eduardo Saback.

Conflicts of Interest: The authors declare no conflict of interest.

Appendix A- Flowchart of research participants.

\section{References}

1. Mottillo S, Bs C, Filion KB, Genest J, Joseph L, Pilote L, et al. The Metabolic Syndrome and Cardiovascular Risk

A Systematic Review and Meta-Analysis. J Am Coll Cardiol. 2010;56(14):1113-32. DOI:

10.1016/j.jacc.2010.05.034

2. Stern MP, Williams K, González-Villalpando C, Hunt KJ, Haffner SM. Does the metabolic-syndrome improve 
identification of individuals at risk of type 2 diabetes and/or cardiovascular disease? Diabetes Care. 2004;27(11):2676-81.

3. Gami AS, Witt BJ, Howard DE, Erwin PJ, Gami LA, Somers VK, et al. Metabolic Syndrome and Risk of Incident Cardiovascular Events and Death. A Systematic Review and Meta-Analysis of Longitudinal Studies. J Am Coll Cardiol. 2007;49(4):403-14. DOI: 10.1016/j.jacc.2006.09.032

4. Grundy SM, Cleeman JI, Daniels SR, Donato KA, Eckel RH, Franklin BA, et al. Diagnosis and Management of the Metabolic Syndrome. Circulation. 2005;112:2735-52. DOI: 10.1161/CIRCULATIONAHA.105.169404

5. Moore JX, Chaudhary N, Akinyemiju T. Metabolic Syndrome Prevalence by Race/Ethnicity and Sex in the United States, National Health and Nutrition Examination Survey, 1988-2012. Prev Chronic Dis. 2017;14(24):1-16. DOI: https://doi.org/10.5888/pcd14.160287

6. Moreira GC, Cipullo JP, Ciorlia LAS, Cesarino CB, Vilela-Martin JF. Prevalence of metabolic syndrome: Association with risk factors and cardiovascular complications in an urban population. PLoS One. 2014;9(9):1-10. DOI: 10.1371/journal.pone.0105056

7. Chini LSN, Greffin S, Lugon JR. Prevalence of metabolic syndrome among workers from the Company of Generation and Distribution of Energy in Rio de Janeiro, Brazil. Cad Saúde Coletiva. 2014;22(4):359-64. DOI:

\section{$10.1590 / 1414-462 X 201400040009$}

8. Vidigal FDC, Bressan J, Babio N, Salas-salvadó J. Prevalence of metabolic syndrome in Brazilian adults : a systematic review. BMC Public Health. 2013;13:1-10.

9. Agyemang-Yeboah F, Eghan BAJ, Annani-Akollor ME, Togbe E, Donkor S, Oppong Afranie B. Evaluation of metabolic syndrome and its associated risk factors in type 2 diabetes: A Descriptive Cross-Sectional Study at the Komfo Anokye Teaching Hospital, Kumasi, Ghana. Biomed Res Int. 2019;2019. DOI: https://doi.org/10.1155/2019/4562904 
10. Brasil. Vigitel Brasil 2018: vigilância de fatores de risco e proteção para doenças crônicas por inquérito telefônico: estimativas sobre frequência e distribuição sociodemográfica de fatores de risco e proteção para doenças crônicas nas capitais dos 26 estados b. 2019.

11. Tirupati S, Chua LE. Obesity and metabolic syndrome in a psychiatric rehabilitation service. Aust $\mathrm{N} Z \mathrm{Z}$ Psychiatry. 2007;41(7):606-10.

12. Teixeira PJR, Rocha FL. The prevalence of metabolic syndrome among psychiatric inpatients in Brazil. Rev Bras Psiquiatr. 2007;29(4):330-6.

13. Lemieux I, Pascot A, Couillard C, Lamarche B, Tchernof A, Alméras N, et al. Hypertriglyceridemic Waist. A Marker of the Atherogenic Metabolic Triad (Hyperinsulinemia; Hyperapolipoprotein B; Small, Dense LDL) in Men? Circulation. 2000;102(2):179-84.

14. Consultation WHO. Obesity: preventing and managing the global epidemic. Report of a WHO consultation. World Heal Organ - Tech Rep Ser. 2000;894.

15. Nashwa Masnoon, Sepehr Shakib, Lisa Kalisch-Ellett GEC. What is polypharmacy? A systematic review of definitions. BMC Geriatr. 2017;17(230):1-10. DOI: 10.1186/s12877-017-0621-2

16. Coutinho LMS, Scazufca M, Menezes PR. Métodos para estimar razão de prevalência em estudos de corte transversal. Rev Saude Publica. 2008;42(6):992-8.

17. Francisco PMSB, Donalisio MR, Barros MB de A, Cesar CLG, Carandina L, Goldbaum M. Medidas de associação em estudo transversal com delineamento complexo: razão de chances e razão de prevalência. Rev Bras Epidemiol. 2008;11(3):347-55.

18. Vancampfort D, Stubbs B, Mitchell AJ, De Hert M, Wampers M, Ward PB, et al. Risk of metabolic syndrome and its components in people with schizophrenia and related psychotic disorders, bipolar disorder and major depressive disorder: A systematic review and meta-analysis. Vol. 14, World Psychiatry. 2015. 
19. Lesage A, Rochette L, Émond V, Pelletier É, St-Laurent D, Diallo FB, et al. A surveillance system to monitor excess mortality of people with mental illness in Canada. Can J Psychiatry. 2015;60(12):571-9.

20. Kyu HH, Abate D, Abate KH, Abay SM, Abbafati C, Abbasi N, et al. Global, regional, and national disability-adjusted life-years (DALYs) for 359 diseases and injuries and healthy life expectancy (HALE) for 195 countries and territories, 1990-2017: A systematic analysis for the Global Burden of Disease Study 2017. Lancet. 2018;392(10159):1859-922.

21. Charlson FJ, Moran AE, Freedman G, Norman RE, Stapelberg NJC, Baxter AJ, et al. The contribution of major depression to the global burden of ischemic heart disease: A comparative risk assessment. BMC Med. $2013 ; 11(1)$

22. Walburg FS, Van Meijel B, Van Tulder MW, Adriaanse MC. Cost-effectiveness of a lifestyle intervention for people with a serious mental illness (SMILE): Design of a pragmatic cluster-randomised controlled trial. BMC Psychiatry. 2019;19(1):1-8. DOI: https://doi.org/10.1186/s12888-019-2132-5

23. Looijmans A, Jörg F, Bruggeman R, Schoevers RA, Corpeleijn E. Multimodal lifestyle intervention using a web-based tool to improve cardiometabolic health in patients with serious mental illness: Results of a cluster randomized controlled trial (LION). BMC Psychiatry. 2019;19(1):1-12. DOI: 10.1080/14737175.2017.1325321

24. Vancampfort D, Solmi M, Firth J, Vandenbulcke M, Stubbs B. The Impact of Pharmacologic and Nonpharmacologic Interventions to Improve Physical Health Outcomes in People With Dementia: A Meta-Review of Meta-Analyses of Randomized Controlled Trials. J Am Med Dir Assoc. 2020; 53-66.

25. De Rosa C, Sampogna G, Luciano M, Del Vecchio V, Pocai B, Borriello G, et al. Improving physical health of patients with severe mental disorders: a critical review of lifestyle psychosocial interventions. Expert Rev Neurother. 2017;17(7):667-81. DOI: 10.1080/14737175.2017.1325321

26. Holt RIG, Hind D, Gossage-Worrall R, Bradburn MJ, Saxon D, McCrone P, et al. Structured lifestyle education 
to support weight loss for people with schizophrenia, schizoaffective disorder and first episode psychosis: The STEPWISE RCT. Vol. 22, Health Technology Assessment. 2018. 1-160 p. DOI: 10.3310/hta22650

27. Hor ESL, Subramaniam S, Koay JM, Bharathy A, Vasudevan U, Panickulam JJ, et al. Improving metabolic monitoring in patients maintained on antipsychotics in Penang, Malaysia. Australas Psychiatry. 2016;24(1):67-71. DOI: 10.1177/1039856215604484

28. Magno Conceição das Merces AICS, Iracema Lua, Dandara Almeida Reis da Silva, Douglas de Souza e Silva, Antonio Marcos Tosoli Gomes, Manuela Conceição das Merces Miranda, Caroline da Silva Barbosa, Lucelia Batista Neves Cunha Magalhaes, Julita Maria Freitas Coelho, Maria Lucia Silva Servo VPF and ADJ. Metabolic Syndrome Among Primary Health Care Nursing Professionals : A Cross-Sectional Population-Based Study †. Int J Environ Res Public Health. 2019;16(2686):1-13. DOI:10.3390/ijerph16152686

29. Poirier J, Kubow S, Noël M, Dupont C, Egeland GM. The hypertriglyceridemic-waist phenotype is associated with the Framingham risk score and subclinical atherosclerosis in Canadian Cree. Nutr Metab Cardiovasc Dis. 2015;25(11):1050-5. DOI: http://dx.doi.org/10.1016/j.numecd.2015.09.004

30. Freitas RS, da Fonseca M de JM, Schmidt MI, Molina M del CB, de Almeida M da CC. Fenótipo cintura hipertrigliceridêmica: Fatores associados e comparação com outros indicadores de risco cardiovascular e metabólico no ELSA-Brasil. Cad Saude Publica. 2018;34(4):1-16. DOI: 10.1590/0102-311X00067617

31. Alosaimi FD, Abalhassan M, Alhaddad B, Alzain N, Fallata E, Alhabbad A, et al. Prevalence of metabolic syndrome and its components among patients with various psychiatric diagnoses and treatments: A cross-sectional study. Gen Hosp Psychiatry. 2017;45:62-9. DOI: http://dx.doi.org/10.1016/j.genhosppsych.2016.12.007

32. Filipčić I, Šimunović Filipčić I, Grošić V, Bakija I, Šago D, Benjak T, et al. Patterns of chronic physical multimorbidity in psychiatric and general population. J Psychosom Res. 2018;114:72-80. DOI: 
https://doi.org/10.1016/j.jpsychores.2018.09.011

33. Filipčić IŠ, Bajić Ž, Filipčić I. The onset and accumulation of physical multimorbidity in severe and common mental disorders. Curr Opin Psychiatry. 2020;33(5):484-90. DOI: 10.1097/YCO.0000000000000635 